\title{
OPTIMIZATION OF CUTTING STRATEGIES FOR FORGING DIE MANUFACTURING ON CNC MILLING MACHINE
}

\author{
Shantaveerayya B Hiremath ${ }^{1}$, B. Ramreddy ${ }^{2}$ \\ ${ }^{I}$ Department of mechanical engineering, Guru Nanak Dev engineering college Bidar, Karnataka, India \\ ${ }^{2}$ Associate Professor, department of mechanical engineering, Guru Nanak Dev engineering college Bidar, Karnataka, \\ India
}

\begin{abstract}
In present scenario it is necessary to optimize the cutting strategies for forging die manufacturing on CNC milling machines. Manufacturing of dies has been presenting greater requirements of geometrical accuracy, dimensional precision and surface quality as well as decrease in costs and manufacturing times. In this study, effects of the cutting parameters on geometrical error have been examined on a representative die cavity profile. Design of Experiment Method has been employed to find out the effects of the cutting parameters on the geometrical accuracy of the manufactured cavity profile. Prediction formula is derived to estimate the geometrical error value in terms of the values of the cutting parameters. Validity of the prediction formula has been tested by conducting verification experiments for the representative die geometry and die cavity geometry of a forging part used in industry.
\end{abstract}

Keywords: Forging Dies, Milling Process, Geometrical accuracy, Surface roughness.

\section{INTRODUCTION}

Forging is a metal forming process in which a piece of metal is processed to the desired shape by plastic deformation. The process includes sequential deformation steps to the final shape [2]. In forging process, compressive force may be provided by means of manual or power hammers, hydraulic, mechanical or special forging presses. The process of deformation is normally but not always, performed by preheating the metal to a desired temperature before it is worked. Forging technology has a special place compared to all manufacturing processes, because it helps to produce parts of superior mechanical properties with minimum waste of material. Forging process reveal the opportunity to produce complex parts with desired directional strength, refining the material grain structure and developing the optimum grain flow within the material, which imparts desirable directional properties. Forging products are free from undesirable internal voids and have the maximum strength in the vital directions as well as a maximum strength to weight ratio.

Die manufacturers aim to obtain high geometrical accuracy and surface quality in die cavities by utilizing proper cutting strategies and parameters; however, there may exist geometrical discrepancy between surface profile of the designed and the manufactured die cavity. The effects of the input cutting parameters on geometrical accuracy of a specific cavity profile can be analyzed to minimize this geometrical discrepancy.

\section{LITERATURE REVIEW}

Modern CAM software for the programming of $\mathrm{CNC}$ milling-tools provides the possibility of producing various tool paths for the tool, all leading to similar results. The characteristic shape of the tool path is described by the term milling strategy. When working on conventional machines, this strategy did not normally take importance because, in most cases, there were very simple possibilities for control. Nowadays, this is completely different on CNC machines because the controls enable various possibilities for toolcontrol within the workspace [1].

\section{Cutting Parameters in CNC Milling}

Various cutting parameters of CNC milling technology influence the quality of the final part and its manufacturing economy.

- The depth of cut. The depth of cut influences surface quality in an indirect way. Increasing the depth of cut increases the cutting resistance and the amplitudes of any vibrations. The cutting temperature also rises. Therefore, it is expected that the surface quality will deteriorate.

- The feed-rate per cutter tooth. Experiments show that, as the feed-rate increases the surface roughness also increases. In any case, using feed-rates under a certain limit does not yield any substantial improvement in surface quality.

- The cutting speed. An increase of cutting speed generally improves surface quality.

- Stepover of tool: Radial engagement of tool with the workpiece is called stepover.

- The cutting-tool wear. The irregularities of the cuttingedge due to wear are reproduced on the machined surface.

And also, as tool-wear increases, other dynamic phenomena such as excessive vibration will occur, further reducing the grade of surface quality.

- The use of cutting-fluid. The cutting-fluid is generally advantageous in regard to surface roughness because it affects the cutting process in three different ways. 


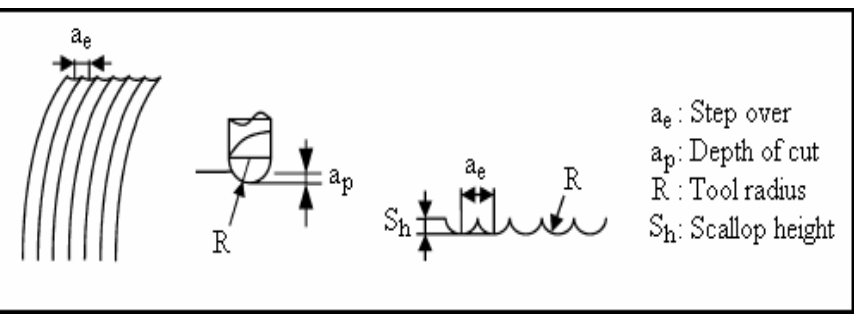

Fig 1: Scallop formations during ball nose finishing.

For the machining of an active tool surface, two technological processes are used [1]: electrical discharge machining and high-speed milling. We can compare these two processes. For the selection of the most appropriate die cavity manufacturing technology, energy consumption and ecology are of a great importance too. It is well known that the EDM process is a very high level of energy consumption process. Therefore, it should be used only in some cases where, concerned product, milling tool shape or die related properties do not allow the $\mathrm{CNC}$ milling applications.

From ecology point of view HSC technology is overcoming EDM for the following reasons:

- Technology using less energy is much more friendlier to the environment.

- Decrease in cutting lubricants and coolants leads to dry machining.

- There must be constant inspection of EDM electrolyte during the process as later on for the waste treatment and disposal [3].

Many researchers have also worked on the optimization of feed rate and tool path strategy to achieve improvements on production time. Linjian Yang, Jinchun Feng deal with feed rate optimization for 5-axis ball-end milling of sculptured surfaces [5]. P.E. Romero, R. Dorado, F.A. Diaz, E.M. Rubio focused on influence of pocket geometry and tool path strategy in pocket milling operation[6].

\section{GEOMETRIC DIMENSIONING \\ TOLERANCING IN FORGING DIES}

AND

Brief information about geometric dimensioning and tolerancing has been presented to provide background knowledge for the current study. The design considerations for forging die cavities have been given to relate geometric dimensioning and tolerancing with forging die cavity design.

\subsection{Definition of Geometric Dimensioning and}

\section{Tolerancing}

Geometric dimensioning and tolerancing (GD\&T) is a symbolic language. It is used to define the nominal geometry of parts and assemblies to define the allowable variation in form and possible size of individual features and to define the allowable variation between features [7]. The features toleranced with GD\&T reflect the actual relationship between mating parts.
Drawings with appropriately applied geometric tolerancing provide the best opportunity for uniform interpretation and cost effective assembly [8].

\section{OBJECTIVES}

$>$ Recent need of die and mould manufacturing can be summarized as:

1. Maintaining geometrical accuracy

2. High quality die surfaces

3. Reduction in production time.

$>\quad$ The important objective of this particular study is to find out geometrical discrepancy between CAD model of a die cavity and a manufactured die cavity by utilizing various cutting parameter values for the finish cut operation of precision forging dies.

$>\quad$ Optimum cutting strategy for rough machining of the defined experimental die cavity geometry will be investigated and feed rate optimization will be performed on the tool path generated. Details of the process analysis for finish cutting operation and geometrical error analysis for the manufactured die cavity.

$>\quad$ The study includes comparison of the milling approaches of a particular curved surface and also according to comparison results; an appropriate milling approach is chosen to conduct experiments to analyze the influence of the milling parameters on the average surface roughness $(\mathrm{Ra})$ and derive a mathematical formula for $\mathrm{Ra}$ prediction within the defined parameters limits for the chosen milling method.

$>$ Experimentation to verify for the representative die cavity geometry and cavity geometry of a forging part used in industry will be performed to check the validity of the acquired formula.

\section{MEASUREMENT OF SURFACE QUALITY}

"The surface quality is identified by surface roughness parameters. The average surface roughness $(\mathrm{Ra})$ is used in this study, as it is the most commonly used roughness parameter in the industry".

\subsection{Common Parameters of Roughness}

In order to describe surface roughness, using the mean line to provide a datum, it is possible to give the surface finish profile a numerical value. The followings are the most commonly used values.

a) Average Roughness (Ra): It is the arithmetic mean of the departures of the profile from the mean line and shown in below figure. Ra value is the most used, and universally known, international parameter of roughness [9].

b) Root mean square (RMS) roughness $(\mathbf{R q})$ : It is the root mean square average of the roughness profile ordinates.

c) Mean roughness depth $(\mathbf{R z})$ : It is the average of single peak to valley heights from five adjoining sampling lengths. 


\subsection{Mitutoyo surftest sj-210}

In order to compare the quality of the die surfaces obtained on the specimen after finish cut, the $\mathrm{Ra}$ values of the divisions were measured as $\mathrm{Ra}$ is the most commonly used factor to identify the surface roughness. The average roughness $(\mathrm{Ra})$ values are measured using "Mitutoyo surftest SJ-210" [10] stylus type surface roughness measuring equipment present in Guru Nanak Dev engineering college, Bidar.

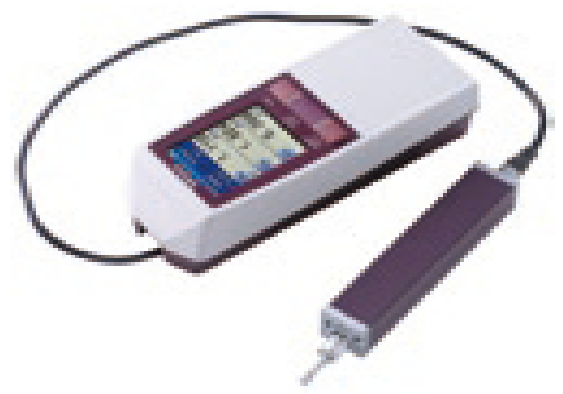

Fig 2: Mitutoyo surftest SJ-210

\section{METHODOLOGY}

Diagram below shows the steps involved in this experiment [9].

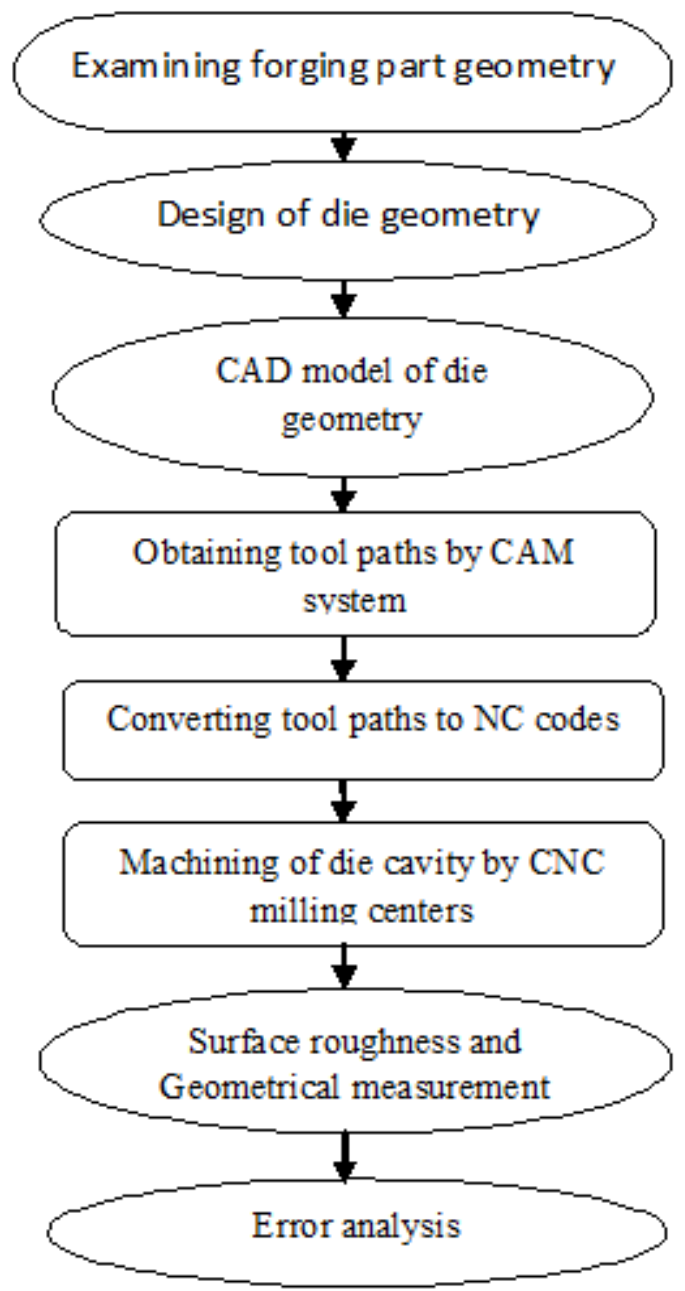

\subsection{Determination of the Experimental Geometry} for the Study [2]

According to the observations made, it can be concluded that the experimental profile must involve three types of surfaces to represent forging die cavities. These surfaces are:

- Horizontal surfaces

- Surfaces of fillets and corner radii greater than $2 \mathrm{~mm}$ radius)

- Nearly vertical surfaces (draft surfaces with draft angles between $3^{\circ}$ to $7^{\circ}$ )

By keeping the considerations above in mind, a profile is designed to analyze the geometrical error between the CAD profile and the manufactured profile. By rotating this experimental profile around $\mathrm{Z}$ axis, an axisymmetric die cavity geometry presented in figure is obtained.

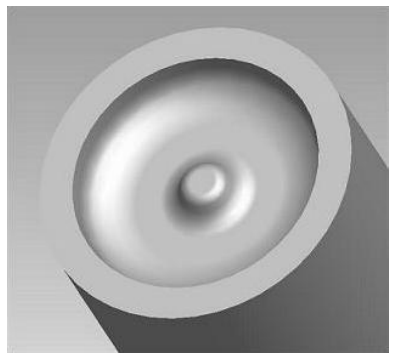

Fig 3: CAD profile of experimental die cavity

\subsection{Selection of Material}

From examining the previous studies the material selected is cold work die steel material (D-3).Composition, properties and some of the applications of selected material are listed below.

\subsubsection{Properties of D3 die steel [11]}

\section{Composition:}

\begin{tabular}{|l|l|l|l|l|l|l|l|l|}
\hline Element & $\mathrm{C}$ & $\mathrm{Mn}$ & $\mathrm{Si}$ & $\mathrm{Cr}$ & $\mathrm{Ni}$ & $\mathrm{W}$ & $\mathrm{V}$ & $\mathrm{Cu}$ \\
\hline Weight\% & 2.35 & 0.60 & 0.60 & 12 & 0.30 & 1 & 1 & 0.25 \\
\hline
\end{tabular}

\subsubsection{Mechanical Properties}

\begin{tabular}{|l|l|}
\hline Density $\left(\times 1000 \mathrm{~kg} / \mathrm{m}^{3}\right)$ & $\mathbf{7 . 7}$ \\
\hline Poisson's Ratio & $0.27-0.30$ \\
\hline Elastic Modulus $(\mathrm{GPa})$ & $190-210$ \\
\hline
\end{tabular}

Hot die steel is selected due to,

$>$ On the basis of literature review

$>$ Dimensionally stable throughout heat treatment and coating operations

$>$ Good resistance to hot wear and plastic deformation

$>$ Highly tough and ductility in all directions

$>$ Good high temperature strength

$>$ Improved die life

$>$ Excellent hardenability. 


\begin{tabular}{|l|l|l|}
\hline $\begin{array}{l}\text { MATERIAL } \\
\text { TYPE }\end{array}$ & $\begin{array}{l}\text { SPECIFICAT } \\
\text { ION }\end{array}$ & APPLICATIONS \\
\hline $\begin{array}{l}\text { Cold work } \\
\text { tool steel }\end{array}$ & D-3 & $\begin{array}{l}\text { High efficiency cutting } \\
\text { tools (Dies and } \\
\text { punches) blanking } \\
\text { tools, cold rolls for } \\
\text { multiple roller stands. }\end{array}$ \\
\hline
\end{tabular}

\subsection{Machining of Experimental Die Cavities}

\subsubsection{Rough Cut Milling of Experimental Die}

\section{Cavities}

For the milling process, maximizing metal removal rate is the basic goal in rough cutting operations. There are many parameters influencing the characteristics of milling process. However, when the cutting parameters are considered, main parameters can be classified as [12]:

- Axial depth of cut (ap) [mm]

- Radial depth of cut (ae) [mm]

- Feed rate (Vf) $[\mathrm{mm} / \mathrm{min}]$

- Cutting speed $(\mathrm{Vc})[\mathrm{m} / \mathrm{min}]$

- Type of milling i.e. down or up milling.

\subsubsection{Finish Cut Milling of Experimental Die}

\section{Cavities}

In order to examine the effects of the cutting parameters; step over, feed and cutting speed to the geometric error during finish cut of the forging die cavities.

The input parameters; step over, feed and cutting speed are all quantitative factors that level values of each should be properly defined. Improper selection of the level values and/or determination of level limits may result in incompatible results of the response variable which is undesirable.

As mentioned previously, two levels are decided to be practical for the third input parameter. Therefore, low level i.e. $130 \mathrm{~m} / \mathrm{min}$ and high level i.e. $170 \mathrm{~m} / \mathrm{min}$ are chosen for the cutting speed. Variable factors considered in the finish cut experiments and the selected levels are summarized in tables.

\begin{tabular}{|l|l|l|l|}
\hline Levels & $\begin{array}{l}\text { Step over, } \\
\mathbf{a}_{\mathbf{e}} \\
(\mathbf{m m})\end{array}$ & $\begin{array}{l}\text { Feed, } \mathbf{f}_{\mathbf{t}} \\
(\mathbf{m m} / \text { tooth) }\end{array}$ & $\begin{array}{l}\text { Cutting } \\
\text { speed, } \\
(\mathbf{m} / \mathbf{m i n})\end{array}$ \\
\hline Low Level & 0.10 & 0.030 & 130 \\
\hline $\begin{array}{l}\text { Intermediate } \\
\text { Level }\end{array}$ & 0.20 & 0.040 & - \\
\hline High Level & 0.30 & 0.050 & - \\
\hline Levels & $\begin{array}{l}\text { Step over, } \\
\mathbf{a}_{\mathbf{e}} \\
(\mathbf{m m})\end{array}$ & $\begin{array}{l}\text { Feed, } \mathbf{f}_{\mathbf{t}} \\
(\mathbf{m m} / \text { tooth) }\end{array}$ & $\begin{array}{l}\text { Cutting } \\
\text { speed, } \\
(\mathbf{m} / \mathbf{m i n})\end{array}$ \\
\hline Low Level & 0.10 & 0.030 & 170 \\
\hline $\begin{array}{l}\text { Intermediate } \\
\text { Level }\end{array}$ & 0.20 & 0.040 & - \\
\hline High Level & 0.30 & 0.050 & - \\
\hline
\end{tabular}

\subsection{Three Levels Factorial Design}

$3^{\mathrm{k}}$ design is a factorial design [13], that is, a factorial arrangement with $\mathrm{k}$ factors each at three levels. Three levels of the factors are referred as low, intermediate, and high. Each treatment in the $3^{\mathrm{k}}$ design are denoted by $\mathrm{k}$ digits, where the first digit indicates the level of factor $\mathrm{A}$, the second digit indicates the level of factor $\mathrm{B}$ and the $\mathrm{k}^{\text {th }}$ digit indicates the level of factor k. Geometry of 32 design is shown in below figure.

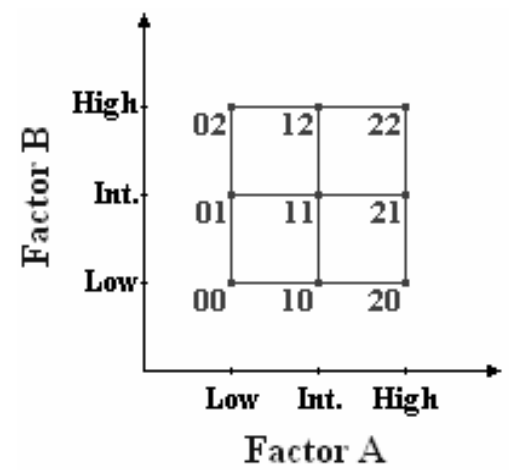

In this study, the simplest design in the $3^{\mathrm{k}}$ system, $3^{2}$ design, which has two factors, each at three levels is performed. Since there are $3^{2}=9$ treatment combinations, there are eight degrees of freedom between these treatment combinations. Main effects of A and B each have two degrees of freedom, and $\mathrm{AB}$ interaction has four degrees of freedom.

\subsection{Machined Part by using above Cutting}

\section{Parameters (Experimentation).}

The factorial design method has been utilized. The design consists of running tests with all the possible combinations of variables at each of three levels, thereby obtaining most of the information required for a multilevel experiment. In that way, the factorial design does an excellent job relating the experimental effort to the information obtained.

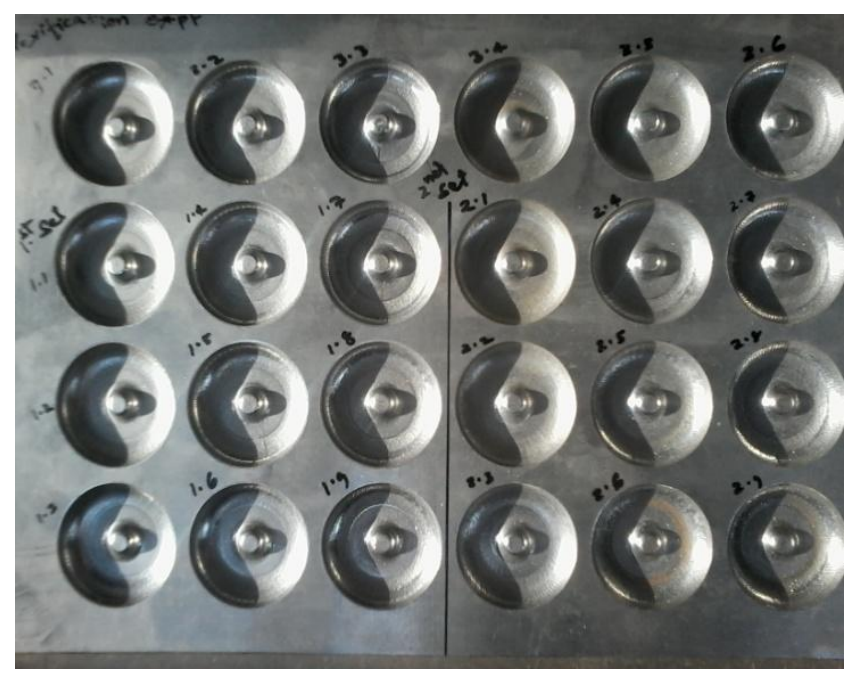

Fig 4: Machined part by using above cutting parameters 


\section{GEOMETRICAL MEASUREMENT}

Precision measurement of the manufactured products in Cartesian coordinate system can be performed by using a coordinate measuring machine (CMM). The available CMM is utilized for the dimensional examination of the experimental die cavities. The available CMM which uses digital readouts, air bearings, computer controls to achieve accuracies in the order of $1 \mu \mathrm{m}$ over spans of $100 \mathrm{~mm}$.

\subsection{Measurement Setup}

For the geometrical error measurement, the experimental work piece is initially fixed on granite plate of the CMM by two mounting clamps to prevent movement of the part on the granite surface. The reference coordinate which is used throughout the machining operations is recreated by forming reference planes on the flat surfaces of the product. By intersecting these two planes then reference coordinate of the machined part is defined and fixed. By converting the CMM coordinate system to the part coordinate system, measuring probe becomes aware of the reference coordinate and angular position of the each axis [14].

\subsection{Scanning Technique on CMM}

Since the experimental cavity geometry is axisymmetric, measurement along a profile would be sufficient to represent the characteristics of the whole die cavity. For the geometrical error analysis of the experimental die cavity, scanning is performed in "two directions" which are orthogonal to each other.

\section{RESULTS AND GRAPHS}

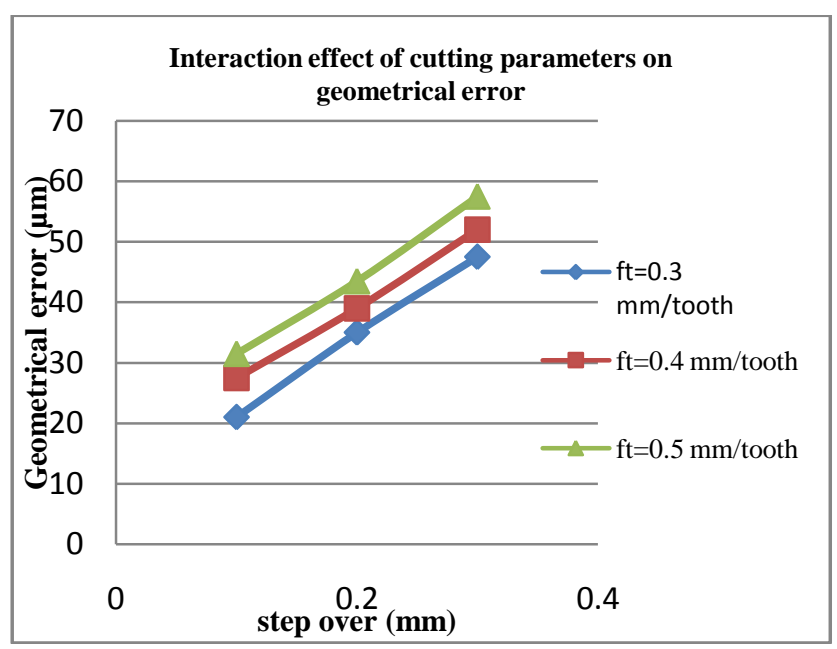

When the interaction effect plot of the cutting parameters is analyzed, it can be concluded that interaction between the step over and the feed is quite low due to the similar shape of the response curves attained from the three levels of the parameters.

\subsection{Interaction Effect of Input Parameters} on

\section{Surface Quality}

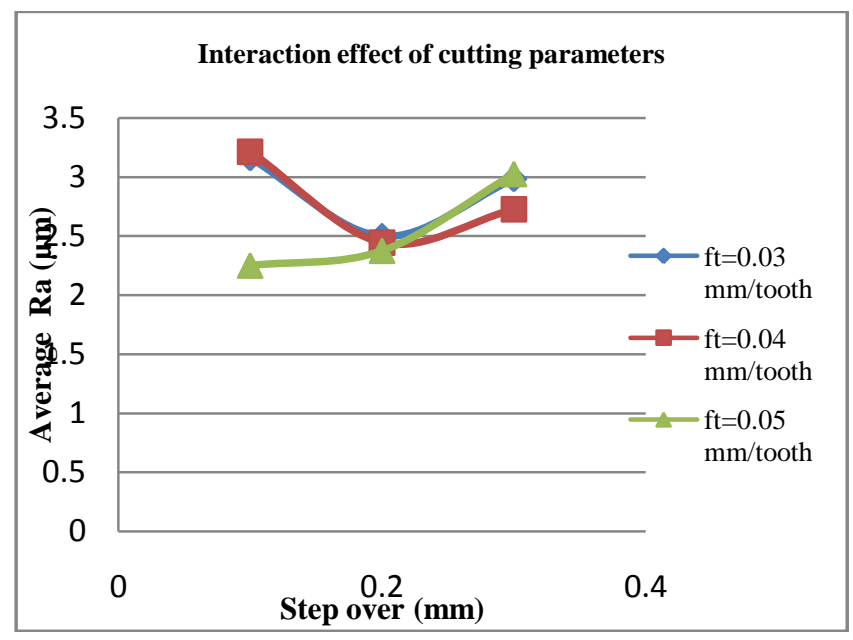

As a result of these experimental analyses, it is clear that the cutting parameters proportionally influence characteristics of the surface profile in terms of geometrical error and surface quality. Keeping these parameters at lower recommended values provides not only excellent geometrical accuracy and surface quality for the forging die cavities but also elimination of manual polishing utilized in forging die production.

\section{CONCLUSIONS AND FUTURE WORK}

In this study, it is aimed to find out the effects of the cutting parameters i.e. step over, feed and cutting speed on geometrical accuracy of the surface profile of forging die cavities. For this purpose, a representative die cavity profile involving major design features of the forging die cavities is initially determined. The geometrical discrepancy between CAD model of the representative die cavity profile and the manufactured profile is examined by utilizing design of experiment approach.

The factorial design is implemented to investigate the influence of the step over, the feed and the cutting speed on the geometrical error and surface quality.

"In the set of experiments where the cutting speed is 130 $\mathrm{m} / \mathrm{min}$ and a $170 \mathrm{~m} / \mathrm{min}$, it is realized that change in the step over is more effective on the geometrical error than the change in the feed. From these observations, it is concluded that low step over values together with slightly high feed values would provide excellent geometrical accuracy and surface quality in a reasonable production time".

For the milling conditions that were analyzed, it was observed that the decrease of value of stepover is improves the surface roughness $(\mathrm{Ra})$ and the effect of the stepover on surface roughness is the most significant effect, among the main effects of the other milling parameters and effects of their interactions. 
Some of the recommended future works are,

This work may be extended for different type and size of milling cutters. By considering the production time with geometrical error and surface roughness, a different technique of design of experiment can be used for analysis.

Cutting parameter values higher than the recommended values may be utilized for the finish cut experiments to investigate the geometrical error.

In the study, the most common used roughness parameter (Ra) is analyzed, other roughness parameters like Rz, Rmax or $\mathrm{Rq}$ can be measured on the machined surfaces and are used for the analysis.

\section{REFERENCES}

[1]. Ivo Pahole, Karl Gotlih, Dejan Studencnik, Joze Balic, Mirko Ficko "Influence of the Milling Strategy on the Durability of Forging Tools". Journal of Mechanical Engineering 57(2011)12, 898-903.

[2]. Arda Ozgen. "Cutting strategies for forging die manufacturing on cnc milling machines".

[3]. B. Kecelj, K. Kuzman, J. Kopac - Speciality of HSC in manufacturing of forging dies. Journal of Materials Processing Technology 157-158 (2004) 536-542

[4]. R.Rajendra, G.Chandramohan reddy, A.M.K.Prasad, K.L.Udaykiran "Study of Surface integrity Characteristics on $\mathrm{Al}$ and Die Steel Components using Copper tool in Sink EDM Process". International Journal of Current Engineering and Technology, feb-2014

[5]. Linjian Yang, Jinchun Feng "Research on Multi-axis CNC Programming in Machining Large Hydraulic Turbine's blades Based on UG" International Conference on Advances in Engineering-24 (2011) 768 - 772.

[6]. P. FallboÈhmer, C.A. RodroAguez, T. OÈ zel, T. Altan."High-speed machining of cast iron and alloy steels for die and mold manufacturing" Journal of Materials Processing Technology 98 (2000) 104-115.

[7]. P.E. Romero, R. Dorado, F.A. Diaz, E.M. Rubio "Influence of pocket geometry and tool path strategy in pocket milling of UNS A96063 alloy". Procedia Engineering 63 (2013) 523 - 531

[8].Wikipedia,website:http://en.wikipedia.org/wiki/Geometr ic_Dimensioning_and_Tolerancing.

[9]. Gene R. Cogorno, "Geometric Dimensioning and Tolerancing for Mechanical Design” (2006), McGraw-Hill Mechanical Engineering Design.

[10]. Kazim Arda Celik "Development of a methodology for prediction of surface roughness of curved cavities manufactured by 5 -axes cnc milling".

[11]. Mitutoyo website: http://www.mitutoyo.com.br/site/pdf/novos/E4388-sj-

210pdf.

[12]. Website: www.efunda.com.

[13]. S. Rammohan Reddy, R. Rama Krishna Reddy "Cutting Strategies for Casting Die Manufacturing on CNC Milling Machine" IOSR Journal of Mechanical and Civil Engineering, Vol 7, Issue 4, (Jul. - Aug. 2013) 15-23.
[14]. "Design and Analysis of Experiments by Douglas Montgomery: a supplement for using JMP", New York Wiley (2001).

[15]. Website: http://www.freepatents online.com. 